AD WATCH

\title{
Is "YouTube" telling or selling you something? Tobacco content on the YouTube video-sharing website
}

\author{
Becky Freeman, Simon Chapman
}

Tobacco Control 2007;16:207-210. doi: 10.1136/tc.2007.020024

W ith advertising bans eroding direct tobacco advertising and promotional opportunities, tobacco companies are embracing more covert means of keeping their products in the minds of current and potential consumers. Compared with the breadth of published research on "above-the-line" tobacco advertising, research examining "below-the-line"1 indirect forms of tobacco promotion is in its infancy. Promotions at dance parties, ${ }^{2}$ themed nights in hip clubs, ${ }^{3}$ bars and music festivals, ${ }^{4}$ and disguising market research as sampling promotions ${ }^{5}$ are examples of identified strategies. Just as tobacco company marketers have infiltrated youth-friendly venues, it is conceivable that they also have a presence on youth-friendly websites. While the world wide web (WWW) is being used extensively to sell cigarettes, ${ }^{6}$ its largely unregulated status holds much potential as a vehicle for both promoting smoking and particular brands of tobacco products, and for promoting antismoking discourse.

The WWW is no longer a vehicle to simply retrieve information and purchase goods, it is now a fully interactive and participatory platform. ${ }^{7}$ Coined in 2004 as Web 2.0, the WWW is increasingly being driven by consumer-generated content. ${ }^{8}$ It is both timely and critical to examine tobacco marketing in the Web 2.0 era. We are particularly interested in websites that appeal to youth and young adults, the same target population for tobacco companies. Internet use by young people is part of their everyday life; in 2006, more than half of youth and young adult Australians (aged 15-24 years) used the internet on a daily basis. ${ }^{9}$ The website YouTube (www.youtube.com) is an ideal example of a youth-friendly website that embodies the Web 2.0 principles of participation. It has the potential to be a fruitful place for tobacco marketers to turn their efforts.

\section{What is YouTube?}

YouTube was founded in February 2005, as a "consumer media company for people to watch and share original videos worldwide through a web experience ${ }^{\prime \prime} .{ }^{10}$ YouTube is a free service where subscribers can upload videos of any quality (including those shot using mobile phone video recorders), thereby sharing them with a potential audience numbering hundreds of millions. Links to newly posted videos enjoyed by viewers can be easily emailed to others, resulting in popular videos rapidly coming to the attention of large numbers of viewers. Originally intended exclusively for the sharing of consumer-generated videos, the site has evolved rapidly into a highly popular "entertainment destination", which includes clips from television programmes, movies, sporting events and popular music.

YouTube has experienced an explosive rise in use. YouTube was the fastest growing website from January to June 2006, increasing its browsership by $297 \%$, from a monthly unique audience of 4.9 million to 19.6 million. ${ }^{11}$ A greater proportion of 12-17-year olds have visited YouTube than any other demographic group, being 1.5 times more likely than the average web user to visit the site. ${ }^{11}$

Its immense success saw Google Inc (the world's leading web search engine ${ }^{12}$ ) acquire the site on 13 November 2006 for US\$1.65 billion. ${ }^{13}$ Besides selling advertising space on the site, income is derived from partnerships with several US entertainment corporations (Columbia Broadcasting System, National Broadcasting Company, Universal Music group, Sony BMG Music Entertainment Group and The National Hockey League) which have video content agreements with YouTube. ${ }^{14}$ Some of these agreements include advertising partnerships where revenue from advertisements that appears next to the videos is shared between YouTube and the company that supplied the video.

YouTube is not the only website that relies on consumers to provide the bulk of the site content. Social networking sites such as MySpace (www.myspace.com) and knowledge-sharing sites such as Wikipedia (www.wikipedia.org) allow thousands of people to share opinions, stories, information and entertainment in a largely unrestricted environment. This unprecedented ability for any one person to share his or her experiences with millions of others, both inexpensively and instantaneously, is undoubtedly attractive to manufacturers and marketers of consumer goods. Time magazine named its Person of the Year for 2006 "You", in light of the growing popularity and powerful influence of consumer-generated content websites such as YouTube. ${ }^{15}$

Given the potential for the anonymous exploitation of YouTube (including by tobacco companies) to reach a massive audience, particularly youth, by both promoting and culturally undermining smoking, this paper analyses the content of smoking imagery on YouTube.

\section{Methods}

Searches for videos with smoking content were conducted on the YouTube website on 30 November 2006. Two separate search methods were used. First, the search term "smoking" was

Abbreviations: WOMMA, The Word of Mouth Marketing Association; WWW, world wide web 
entered into the site's search engine. We chose the search term "smoking" because it would capture both prosmoking and antismoking videos. This enabled us to assess what type of content a YouTube user interested in smoking would most likely view. This search string also captures all similar words such as smoke, smoky and smoker. The results were sorted using two of the site's sort functions: relevance and number of views. On the assumption that few users would look at $>50$ videos, we viewed the first 50 videos obtained for each of the two sorts and classified them according to whether they contained tobacco smoking imagery. Initially, all the videos were screened by the lead researcher; each video was watched twice and the name of the video, a summary of the video content, the webpage link and total number of views were recorded in an Excel spreadsheet. After the initial screening, the videos that were found to contain tobacco smoking imagery were watched by both researchers independently. All videos containing tobacco smoking were then assigned to one of six categories on the basis of the content of the video (table 1). These six categories were determined after watching all the tobacco smoking videos, and were chosen on the basis of the primary themes that emerged.

Next, the 50 most viewed videos of all time, regardless of topic or category, on the YouTube site were assessed for smoking imagery. Any smoking images found were recorded and summarised.

Viewers are able to post feedback on the video as either text or video comments. Comments on the smoking videos were classified as positive, negative or neutral, on the basis of viewer support of the portrayal of smoking in the video.

\section{Results}

The search term "smoking" returned 29325 videos. Of the first 50 videos retrieved and assessed by relevance, 24 contained cigarette smoking imagery, 2 cigar smoking imagery and 21 marijuana smoking imagery. The remaining three videos contained images of smoke coming from either vehicles or fires. The search results were independent of one another-for example, no video contained both cigarette and marijuana smoking imagery. Table 1 summarises the 26 (52\%) videos that contained tobacco (cigarette and cigar) smoking imagery, when sorted by relevance.

When the videos were sorted by the number of times the video had been viewed, the results were very different. Only one video (that of a female smoking) appeared in both lists. Of the first 50 videos assessed by number of views, 13 contained cigarette smoking imagery, 1 contained bidi smoking imagery and 8 contained marijuana smoking imagery. The remaining 28 videos contained either the word smoke or smoking in the video title or description, but had no smoking imagery. Table 1 summarises the 14 videos that contained tobacco smoking imagery when sorted by number of views.

The most popular of all YouTube videos can also be sorted by total views, regardless of subject matter, allowing viewers to see the most popular videos on the site. The 50 most viewed videos were also examined for smoking content and classified in one of four categories: advertisement, commercial entertainment, music video or personally generated media. Two of these (both music videos) contained smoking imagery. The first video (number 33 most watched, with 4304381 views) was the Gnarls Barkley song, Crazy (http://www.youtube.com/ watch? $\mathrm{v}=$ nekInx7DVOo $)$. The unofficial online version of this music video features animated images of every day objects appearing randomly in time with the music. Two of these objects were cigarettes, with one having the " $\mathrm{X}$ " symbol put through it. The second video (number 48 most watched, with 3749987 views) was the Don Omar song, Angelito Vuela (http://www.youtube.com/watch?v = GFaWE 7-JVO). Set in Rome, it tells the story of a woman who was infected with HIV. At one point, a man lights a cigarette.

Part of the "community" engagement of YouTube, is the facility for viewers to leave comments and to rate videos on a five-point scale. The majority of the videos featuring smoking that we located had attracted viewer comments. Viewer feedback expressed a wide range of opinions. For example, one of the smoking fetish videos (http://www.youtube.com/ watch? $v=$ ij8rYrYzP0A), which contains images of two women blowing smoke into each others' mouths, had 221033 views and 142 comments. The majority of feedback was positive (eg, "Smokin' HOT HOT HOT. Loved it"). Others were less impressed (eg, "Lung cancer becomes a STD. Nice.") Comments on the most popular antismoking video echoed familiar debates around second-hand smoke legislation (http:// www.youtube.com/watch? $\left.v=j_{-} 46 \mathrm{ECeJ} 2 \_w\right)$. One viewer, wholly unmoved by the video, said, "[Its] only safe until the next round of ridiculously unamerican [sic] laws go onto the books. Soon enough it will be illegal to even close your eyes and think about smoking." This view was balanced by more supportive feedback that recognised the harm of second-hand smoke, "... smoking you sort of submit everyone to your habit with secondhand smoke. My mom died of smoking related

Table 1 Tobacco smoking imagery in the first 50 videos searched by "smoking", and sorted by relevance and number of views

\begin{tabular}{|c|c|c|c|}
\hline Category & Description & $\begin{array}{l}\text { Sorted by relevance (total } \\
\text { views) }\end{array}$ & Sorted by number of views (total views) \\
\hline Antismoking & $\begin{array}{l}\text { Video contains a key message that } \\
\text { smoking cigarettes is dangerous, undesirable, or that } \\
\text { smokers should quit }\end{array}$ & $n=5(5044)$ & $n=3^{*}(348729)$ \\
\hline Female smoking & $\begin{array}{l}\text { Video is not against smoking, and contains } \\
\text { images of females smoking cigarettes }\end{array}$ & $\mathrm{n}=6(89034)$ & $\mathrm{n}=2\left(\begin{array}{lll}131 & 013\end{array}\right)$ \\
\hline Male smoking & $\begin{array}{l}\text { Video is not against smoking, and contains images } \\
\text { of males smoking tobacco products }\end{array}$ & $\mathrm{n}=11(23834)$ & $\mathrm{n}=1(110886)$ \\
\hline Smoking fetish & $\begin{array}{l}\text { Video contains "soft core" sexual content in } \\
\text { addition to cigarefte smoking imagery }\end{array}$ & $\mathrm{n}=4 \dagger(50481)$ & $\mathrm{n}=4 \ddagger(433260)$ \\
\hline Comedy & $\begin{array}{l}\text { Video is a parody or clip from a comedy show or movie, } \\
\text { and contains tobacco smoking imagery }\end{array}$ & - & $\mathrm{n}=3\left(\begin{array}{ll}310 & 122\end{array}\right)$ \\
\hline Magic trick & $\begin{array}{l}\text { Video shows magician conducting a show } \\
\text { using cigarefte smoke as a prop }\end{array}$ & - & $\mathrm{n}=1(171329)$ \\
\hline Total of the 50 downloaded & & $\begin{array}{l}n=26(52 \%)(168393 \text { of } \\
251257)(67 \% \text { of total views) }\end{array}$ & $\begin{array}{l}n=14(26.9 \%)(1505339 \text { of } \\
2260276)(67 \% \text { of total views) }\end{array}$ \\
\hline
\end{tabular}

*Two videos were identical, but were posted by different YouTube users. Combining both, it was the most watched smoking video on YouTube.

tThree of four videos were subsequently banned from YouTube (as of $4 \mathrm{Dec} 2006$ ) due to inappropriate content. Each of these featured women. $\ddagger$ One video was subsequently banned from YouTube (as of 4 Dec 2006) for violation of copyright. 
illness and now my father is on oxygen $24 \mathrm{~h}$ a day. Trust me ... smoking is one of the most dangerous habits you can have."

Further exploration of YouTube revealed several historical cigarette ads. Most of these were archival, historic footage such as Flintstone ads for Winston (http://www.youtube.com/ watch?v = ie5i7dmxdFI) and Virginia Slims ads of the 1960s (http://www.youtube.com/watch?v = Q0g4-3CJytI). A more recent example (from 2001) was a German Players $\mathrm{ad}^{16}$ showing a woman feigning orgasm in a restaurant, while a young man across the room suggestively plays with his cigarettes

(http://www.youtube.com/ watch?v $=$ qMgoxLNQ1 $\mu \mathrm{M})$. It is not possible to determine whether these ads are placed on the site by independent users or tobacco companies. The tobacco companies owning the copyrights do not appear to mind this exposure. A current promotional video for Swedish snus is described in the case study shown in Box 1.

\section{Discussion}

YouTube was conceived as a vehicle for the sharing of amateur videos. Much of its content remains true to the original aim, as several of the videos we examined were clearly of people attempting to entertain and amuse viewers through their own experiences. However, concern has been expressed over the authenticity of the videos on the site, with users and media commentators questioning the extent to which some videos might be covert advertisements posing as either entertainment or consumer-generated media. ${ }^{17}$ Catherine Taylor, ${ }^{18}$ of the marketing trade journal Brandweek, notes that it is possible to "make any ad into one that has all of the attributes of any YouTube video; it can be shared, embedded in other sites and commented upon, with the user firmly at the controls. In short, except for the fact that money changes hands and gives advertisers privileged placements, the content is treated much like user-generated video." Of the top 50 videos viewed of all time, we were able to confirm that six were actually advertisements.

Authenticity and transparency are important to YouTube users. A very popular YouTube video blog, lonelygirl15, was the subject of viewer outrage when her videos were exposed as "flogs" (fake blogs). ${ }^{19}$ Lonelygirlls was posing as a teenage girl who posted video diaries discussing her daily struggle to cope with her conservative parents and teenage angst. In reality, she was an out-of-work actress working with screenwriters to produce the videos. Big corporations have also been exposed for lying about the true origins of blogs that extol the virtues of their products. Both Walmart and Sony paid advertising agencies to create blogs that appeared to be the positive experiences of real people. ${ }^{20}$ "Buzz" marketing backfires when the buzz is no longer about the blog message, but about how the companies tried to dupe and manipulate the consumers.

In an apparent response to consumer concerns about advertising transparency, The Word of Mouth Marketing Association (WOMMA) (http://womma.org/), a marketing and public relations trade organisation, is in the process of developing a code of ethics for companies which employ buzz marketing methods. According to their website, building an ethical industry is a "complicated process", but the spirit of their code is based on honesty and transparency. ${ }^{21}$ Despite WOMMA's concern for consumer protection, it is strongly opposed to any regulation of buzz marketing - a practice it claims is separate from the far more sinister "stealth marketing". $^{22}$ Paradoxically, one of the governing members of WOMMA is Burson-Marsteller, the public relations firm that created Philip Morris's National Smokers Alliance (NSR), a dubious grassroots organisation that opposed indoor smoking bans on the grounds that such regulation was a violation of
American freedom. ${ }^{23}$ The National Smokers Alliance is arguably a text-book example of stealth marketing.

Although we found more prosmoking content in our sample, the antismoking videos were more watched. This was largely due to the popularity of the darkly humorous "balcony ad", where a group of smokers cause a balcony to collapse (http:// www.youtube.com/watch?v = j_46ECeJ2_w). The smoking fetish and female smoking videos were the most watched of those with prosmoking content. Interestingly, none of the fetish videos featured males. Female smoking portrayed as sexy and alluring is a familiar cigarette-marketing stereotype. ${ }^{24}$ None of the prosmoking videos were readily identifiable as tobacco industry creations. However, given the industry's historical use of stealth marketing techniques, we cannot definitively say that there is no tobacco industry presence on YouTube.

\section{Implications for tobacco control}

Several possibilities for action arise for tobacco control. It might be asked whether YouTube ought to be lobbied to broaden its definitions of unacceptable material to include those that depict smoking. The site's code of conduct policy currently outlaws pornography, sexually explicit content, the depiction of dangerous or illegal acts (although we found depictions of apparent cannabis smoking), intentionally shocking or disgusting material, hate speech, racism, animal abuse, bomb making, violence or the "malicious use of stereotypes intended to attack or demean a particular gender, sexual orientation, race, religion or nationality". ${ }^{25}$ Viewers can also click on a link that appears below each video, which flags the video as inappropriate. YouTube states that staff will examine each video that is flagged within 24-48 h. These flags are considered when banning videos and subscribers that violate YouTube rules on sexual content, mature $(>18)$ content, hate speech, copyright infringement, extreme violence or other YouTube content infringement. Smoking does not appear to contravene these guidelines, yet some may argue that the harm caused by smoking warrants prosmoking images being banned from YouTube.

As with the current Smoke Free Movies campaign, YouTube could be urged to adopt a rating system for smoking in videos. ${ }^{26}$ Those not meeting the recommended guidelines for a general audience could be subsequently banned from the site. The counter argument to this approach is that YouTube does not purport to be a site solely for the use of children. Unlike the mass market business of movies, YouTube videos are often produced by individuals without any corporate involvement. If prosmoking videos are indeed genuine consumer-generated media, is it the place for tobacco control to censor these opinions? YouTube is an open forum where tobacco control advocates can post their comments on prosmoking videos and engage in debate with other YouTube users. Tobacco control efforts have not sought to ban prosmoking opinions expressed in mainstream media (newspaper, television, radio), but have rather successfully worked with the media to promote smokefree and antismoking messages. ${ }^{27}$

YouTube is an obvious vehicle for the dissemination of antismoking messages. If this material is entertaining and amusing, it can become very popular, as demonstrated by the success of the smoking balcony ad. Health Canada has placed their latest antismoking ad on YouTube (http://www.youtube. com/watch?v $=-$ DgV_ELfK9c) $_{-}$, and several of the American Legacy Foundation, Truth ads can also be found on the site (http://www.youtube.com/watch?v = zuh2w2sFRMI). Time will tell if these videos prove to be popular among viewers. Producing unique content for YouTube, as opposed to posting already existing television ad campaigns, is a strategy that also needs to be explored and evaluated for effectiveness. 


\section{Box 1: Case study-snus on YouTube}

Swedish snus is being marketed on YouTube. A professionally made, humorous video promoting snus as part of Swedish identity can be viewed here: http://www.youtube.com/ watch? $v=8 x j m 9 N N u u V U(5899$ views as of 4 January 2007).

The ad features an English-speaking actor, at one stage dressed as a physician recommending snus as safe and fun. Women, low users of snus, ${ }^{28}$ are over-represented in the video, and a young attractive woman demonstrates how to insert a snus pouch. Snus is also promoted as a product to use when one is unable to smoke. The snus tins shown are unbranded, but the video production was tagged by "The Northerner, Very Scandinavian". The website for the Swedish registered company, www.northerner.com, sells all things Scandinavian, from food, to crafts to snus. The same snus promotional video found on YouTube is also on the Northerner website alongside a range of branded snus.

The Swedish Tobacco Act" ${ }^{29}$ states that "advertising or other marketing activity may not be obtrusive or soliciting, or encourage the use of tobacco products". The Act also includes provisions requiring "that the packaging of every tobacco product includes a suitable warning text and a contents declaration". The video most certainly encourages people to take up snus, and contains no information about possible health effects or addiction.

Entering "snus" into YouTube's search engine yielded 176 videos. One apparently amateur production (http://www.youtube.com/watch? $v=6$ LcVHRYI6TI) shows a group of young Swedish girls around a party table. Speaking in English, one girl demonstrates how to use snus. Upon inserting the snus pouch, she feigns a theatrical drug-like euphoria, saying "after a few minutes we are feeling the effects of snus. It is really cool." It is possible that this video is an example of stealth marketing of snus.

One of the more popular anti-smoking videos we found (70 001 views) was of an older male who was trying to give up smoking and asked other YouTube users to quit smoking with him on his nominated quit day (http://www.youtube.com/ watch? $\mathrm{v}=$ PalbUkrfI6E). The overwhelming majority of feedback was positive, with several other users posting their own video responses saying that they would join him in quitting. There is potential for a very cost-effective quit campaign to evolve. Smoking cessation organisations will need to avoid the corporate marketing pitfall of hiring actors and being deceitful about the origins of the video content. Working with real people who are actually quitting smoking and producing inexpensive video blogs is another possible way for tobacco control to maximise this new form of media.

\section{Conclusion}

Smoking imagery is prolific and accessible on YouTube. Possible tobacco-control opportunities need to be explored and evaluated.

\section{ACKNOWLEDGEMENTS}

This paper was supported by grant 396402, funded by The National Health and Medical Research Council, Australia, on the future of tobacco control.

\section{Authors' affiliations}

Becky Freeman, Simon Chapman, The University of Sydney, Sydney, New South Wales, Australia

\section{What this paper adds}

The effectiveness of overt tobacco advertising and sponsorship bans is well established. The industry has responded to these bans by implementing "buzz" or "viral" marketing techniques, such as nightclub and dance party promotions. This paper analyses possible tobacco industry content on the burgeoning consumer-generated media website, YouTube. Tobacco control efforts need to embrace this new medium, in order to counter prosmoking messages and maximise media advocacy opportunities.

Competing interests: None declared.

\section{REFERENCES}

1 Carter SM. Going below the line: creating transportable brands for Australia's dark market. Tob Control 2003;12(Suppl 3):iii87-94

2 Darling H, Reeder Al. Use of tobacco products to advertise music events in Dunedin, New Zealand, 2003. Tob Control 2004;13:243.

3 Carter S. Worshipping at the Alpine altar: promoting tobacco in a world without advertising. Tob Control 2001;10:391-3.

4 Hafez N, Ling PM. Finding the Kool Mixx: how Brown \& Williamson used music marketing to sell cigarettes. Tob Control 2006;15:359-66.

5 Goswami H. India: promoting tobacco via 'research'. Tob Control 2006;15:274-5.

6 Knowles JH Jr, Wanke KL, Kawachi I. Internet sales of tobacco: heading off the new Epidemic. J Public Health Policy 2004;25:162-72.

7 Boulos MN, Maramba I, Wheeler S, et al. Wikis, blogs and podcasts: a new generation of Web-based tools for virtual collaborative clinical practice and education. BMC Medical Education 2006;6:41

8 Giustini D. How Web 2.0 is changing medicine. BMJ 2006;333:1283-4.

9 Australian Bureau of Statistics. Household use of information technology. Canberra, Australia: Australian Bureau of Statistics, 2006.

10 About YouTube. http://www.youtube.com/t/about (accessed 28 Mar 2007)

11 Nielsen//Netratings. YouTube U.S. web traffic grows 75 percent week over week, according to nielsen//netratings. New York, 2006. http:// www.netratings.com/pr/pr_060721_2.pdf (accessed 28 Mar 2007).

12 Nielsen//Netratings. Google and Yahoo! Outpace overall search growth and increase market share in March, according to nielsen//netratings, 2006. http:// www.nielsen-netratings.com/pr/pr_060424.pdf (accessed 28 Mar 2007).

13 Enright A. The evolution of GooTube.com. [Cover story]. Marketing News 2006;40:14.

14 Pruitt A. YouTube content pacts likely to avert lawsuits. Dow Jones Newswires 11 Oct, 2006.

15 Grossman L. Time person of the year: you. Time 2006;168:38-41.

16 Washington T. Smoke screen big tobacco is working hard to ensure the whole world will get its taste of freedom. In These Times.com. Hamburg, Germany, 2001. http://www.inthesetimes.com/issue/25/12/washington2512.html (accessed 28 Mar 2007).

17 Blackshaw P. How do we know what's advertising on YouTube? http:// notetaker.typepad.com/cgm/2006/11/post.html (accessed 28 Mar 2007)

18 Taylor CP. Viral theory. Brandweek 2006;47:20-4.

19 Deliso M. LonelyGirl15 just another way to try to get attention. Advertising Age 2006;77:4

20 Consumerist's 10 biggest business debacles [Cover story]. Advertising Age 2006;77:35

21 The WOMMA ethics code. http://www.womma.org/ethics/code/ (accessed 28 Mar 2007).

22 WOMMA Commends FTC: Commission responds to commercial alert, declines to regulate buzz marketing, 2006. http://www.womma.org/news/007117.php (accessed 28 Mar 2007).

23 Rampton S, Stauber J. How big tobacco helped create "the Junkman". PR Watch 2000;7:5-9.

24 Amos A, Haglund M. From social taboo to "torch of freedom": the marketing of cigarettes to women. Tob Control 2000;9:3-8.

25 YouTube community guidelines. http://www.youtube.com/t/ community_guidelines (accessed 28 Mar 2007).

26 Glantz SA, Glantz SA. Smoking in movies: a major problem and a real solution [erratum Lancet 2004;363:250], Lancet 2003;362:258-9.

27 Chapman S, Wakefield M. Tobacco control advocacy in Australia: reflections on 30 years of progress. Health Educ Behav 2001;28:274-89.

28 Foulds J, Ramstrom L, Burke M, et al. Effect of smokeless tobacco (snus) on smoking and public health in Sweden. Tob Control 2003;12:349-59.

29 The Swedish Tobacco Act strengthened most recently in 2005. http:// www.tobaksfakta.org/default.aspx?id=4119 (accessed 28 Mar 2007). 